S2 Appendix. Booklet used for assessment (English).

Translation in English of the booklet used in this study to assess children's psychological and contextual dimensions of HNC. 


\section{You, Nature, and Home}

Name

Class

How much do you agree with the following statements? Cross a box

statements

I like to hear different sounds in nature

llike to see wild flowers in nature

When I feel sad, I like to go outside and enjoy nature

I feel calm when I am out in nature

I enjoy working I

the garden

Collecting rocks and shells is fun (for example stones and feathers) I feel sad when wild animals are hurt

I like to see wild animals live in a clean environment

I like to touch animals and plants

I think it's important to take care of animals

People are part of nature

People cannot live without it plants and animals

Being outdoors makes me happy

My actions will affect nature

Picking up trash on the ground can help the environment People do not have the right to change nature
Agree very Agree
much

Neither agree

nor

disagree
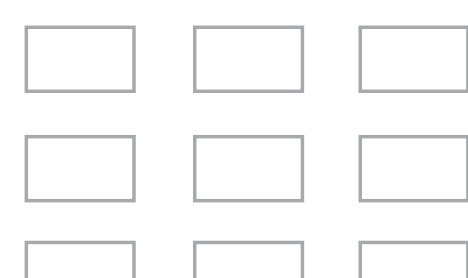

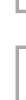

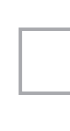

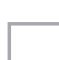
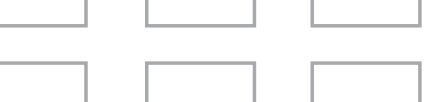

Dagree

Disagree very much
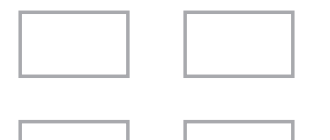

(1)
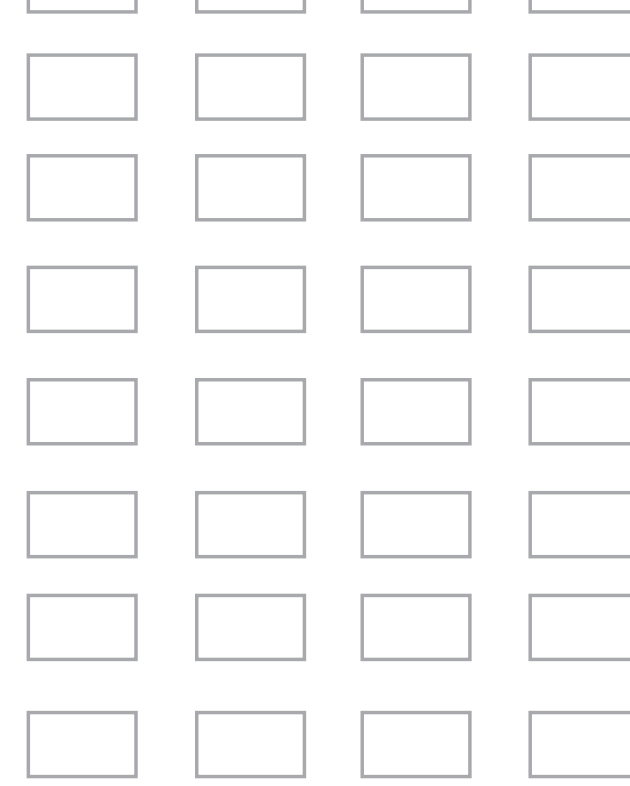
How much do you agree with the following statements? Cross a box

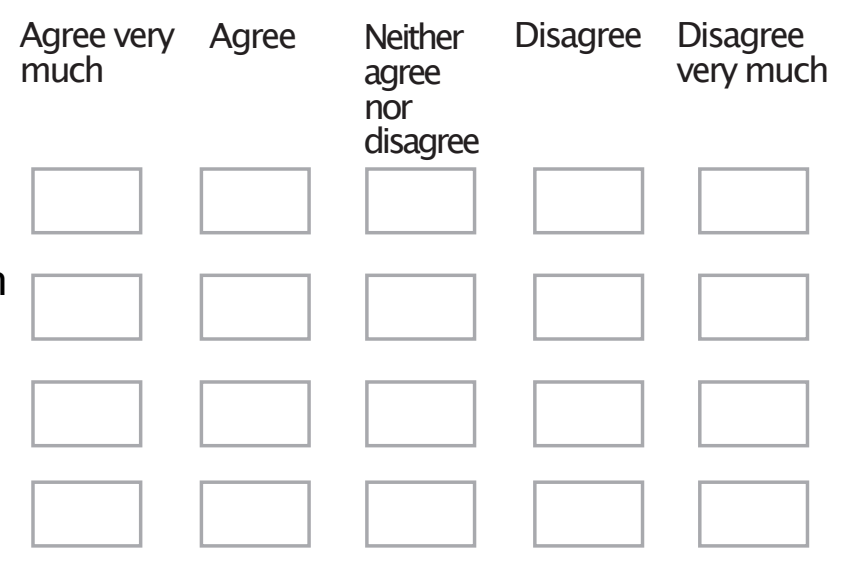

Circle the letter that best describes the relationship between home and nature

I feel sad when salamanders get injured

I like to see salamanders live in a clean environment

I like to touch salamanders

I think it's important to take care of salamanders

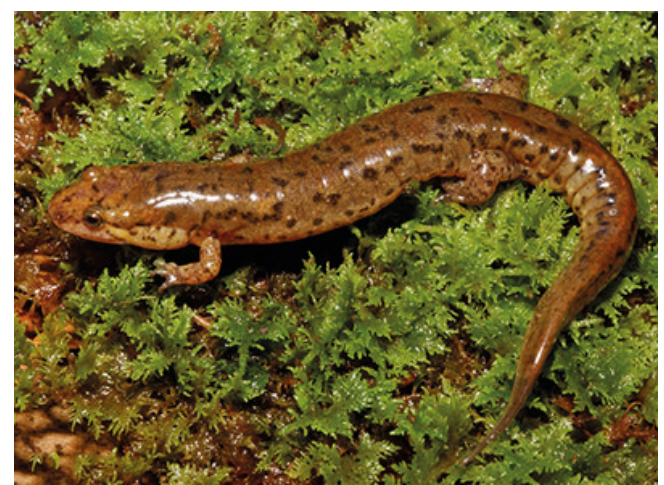

Would you like to work for nature or environmental projects in the futurev?

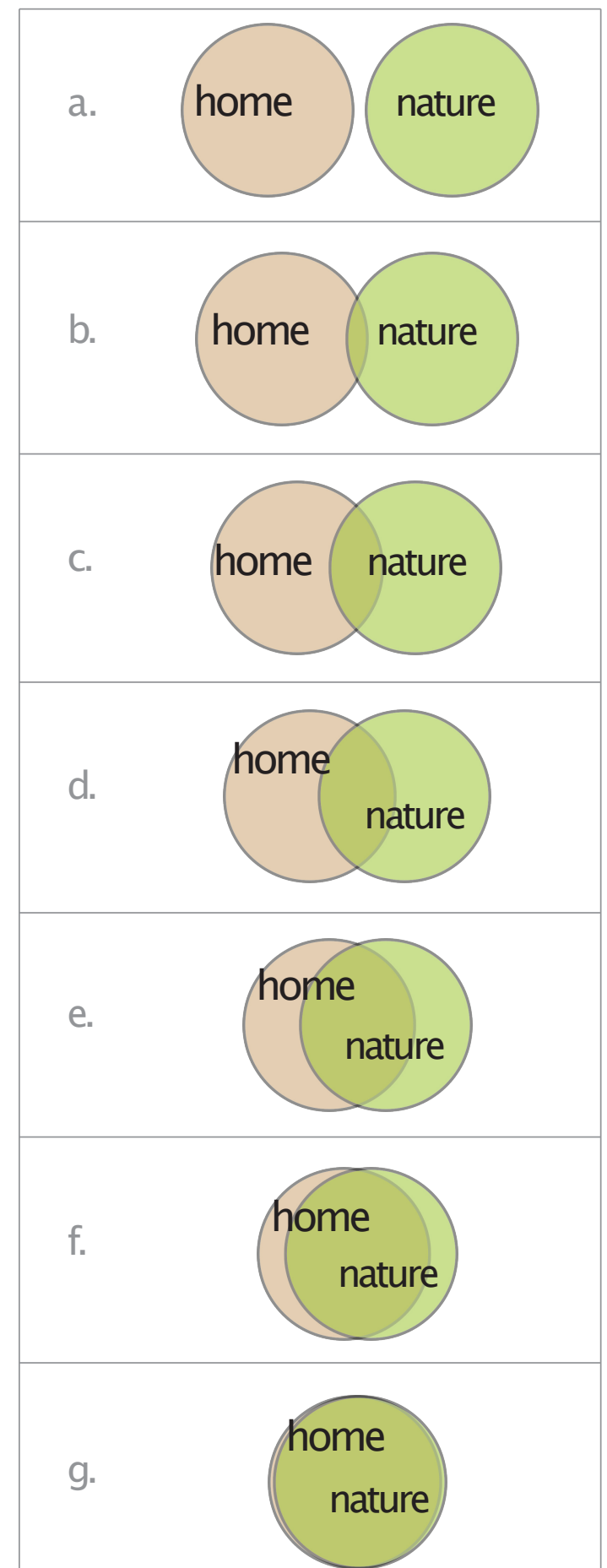


Circle the letter that best describes the relationship between home and city

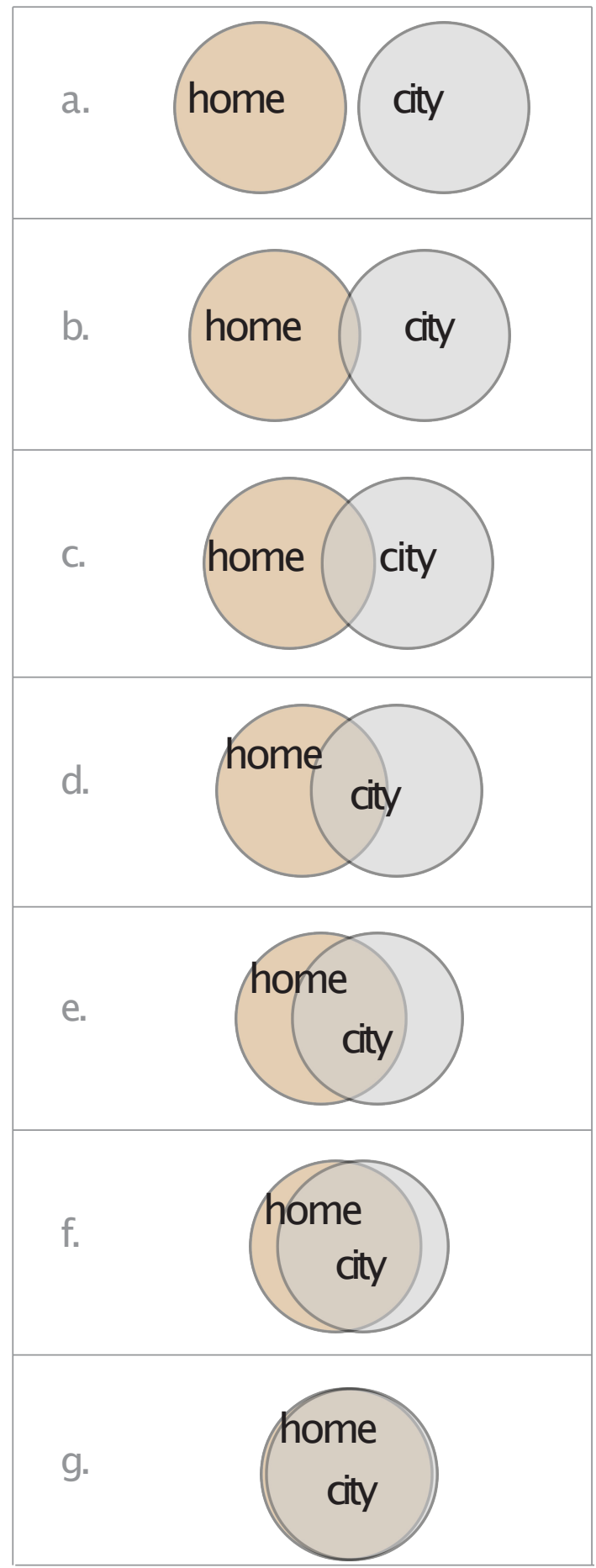

What does the city mean to you?

What is best about the city?

What is worst about the city? 
What does nature mean to you?

What is best about nature?

What is worstabout nature? 
Circle the letter that best describes the relationship between you and nature

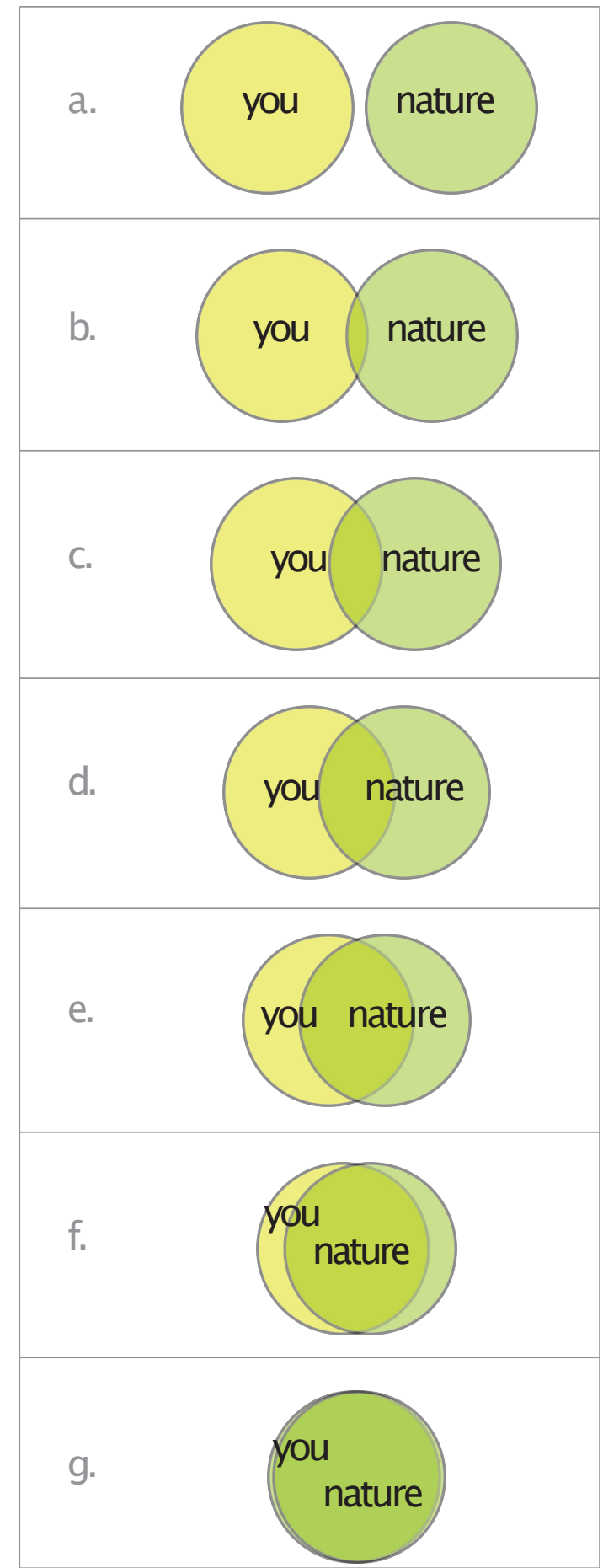

Circle the letter that best describes the relationship between you and city

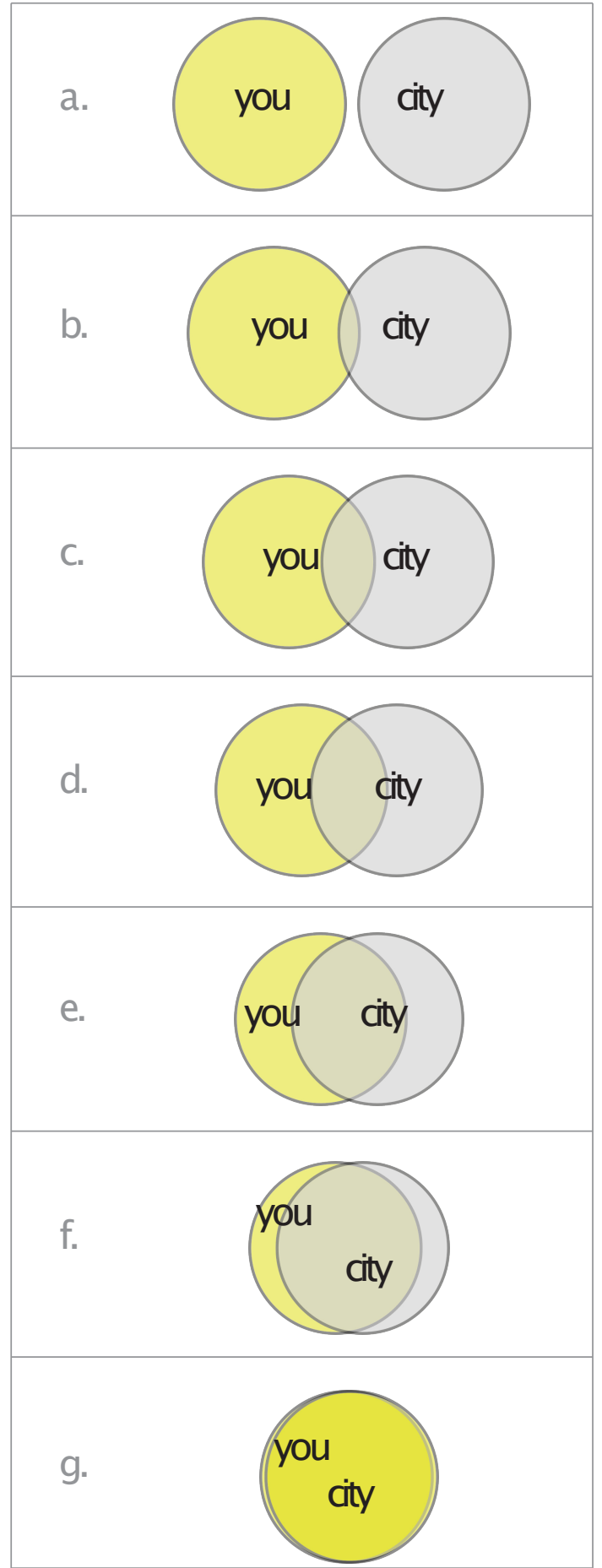

